\title{
Evaluation of in vitro antileishmanial efficacy of cyclosporin A and its non-immunosuppressive derivative, dihydrocyclosporin $A$
}

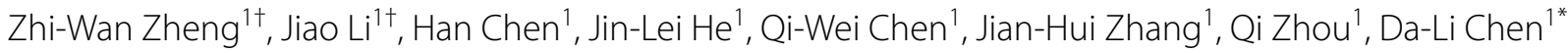 \\ and Jian-Ping Chen ${ }^{1,2^{*}}$
}

\begin{abstract}
Background: New therapeutic drugs are urgently needed against visceral leishmaniasis because current drugs, such as pentavalent antimonials and miltefosine, produce severe side effects and development of resistance. Whether cyclosporine A (CsA) and its derivatives can be used as therapeutic drugs for visceral leishmaniasis has been controversial for many years.
\end{abstract}

Methods: In this study, we evaluated the efficacy of CSA and its derivative, dihydrocyclosporin A (DHCsA-d), against promastigotes and intracellular amastigotes of Leishmania donovani. Sodium stibogluconate (SSG) was used as a positive control.

Results: Our results showed that DHCsA-d was able to inhibit the proliferation of $L$. donovani promastigotes $\left(\mathrm{IC}_{50}\right.$ : $21.24 \mu \mathrm{M}$ and $12.14 \mu \mathrm{M}$ at $24 \mathrm{~h}$ and $48 \mathrm{~h}$, respectively) and intracellular amastigotes (I $\mathrm{C}_{50}: 5.23 \mu \mathrm{M}$ and $4.84 \mu \mathrm{M}$ at 24 and $48 \mathrm{~h}$, respectively) in vitro, but CsA treatment increased the number of amastigotes in host cells. Both DHCsA-d and CsA caused several alterations in the morphology and ultrastructure of L. donovani, especially in the mitochondria. However, DHCsA-d showed high cytotoxicity towards cells of the mouse macrophage cell line RAW264.7, with CC50 values of $7.98 \mu \mathrm{M}(24 \mathrm{~h}$ ) and $6.65 \mu \mathrm{M}(48 \mathrm{~h})$. Moreover, DHCsA-d could increase IL-12, TNF-a and IFN- $\gamma$ production and decrease the levels of IL-10, IL-4, NO and $\mathrm{H}_{2} \mathrm{O}_{2}$ in infected macrophages. On the contrary, CsA decreased $\mathrm{IL}-12$, TNF- $\alpha$, and IFN- $\gamma$ production and increased the levels of IL-10, IL-4, NO and $\mathrm{H}_{2} \mathrm{O}_{2}$ in infected macrophages. The expression of $L$. donovani cyclophilin A ( $L d C y P A)$ in promastigotes and intracellular amastigotes and the expression of cyclophilin A (CyPA) in RAW 264.7 cells were found to be significantly downregulated in the CsA-treated group compared to those in the untreated group. However, no significant changes in LdCyPA and CyPA levels were found after DHCSA-d or SSG treatment.

Conclusions: Our findings initially resolved the dispute regarding the efficacy of CsA and DHCsA-d for visceral leishmaniasis treatment. CSA showed no significant inhibitory effect on intracellular amastigotes. DHCsA-d significantly inhibited promastigotes and intracellular amastigotes, but it was highly cytotoxic. Therefore, CsA and DHCsA-d are not recommended as antileishmanial drugs.

Keywords: Cyclosporine A, Dihydrocyclosporin A, Cyclophilin A, Visceral leishmaniasis

\footnotetext{
*Correspondence: cd11978119@sina.com; jpchen007@163.com

†Zhi-Wan Zheng and Jiao Li contributed equally to this work

1 Department of Pathogenic Biology, West China School of Basic Medical

Sciences and Forensic Medicine, Sichuan University, Chengdu, China

Full list of author information is available at the end of the article
}

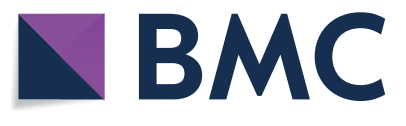

(c) The Author(s) 2020. This article is licensed under a Creative Commons Attribution 4.0 International License, which permits use, sharing, adaptation, distribution and reproduction in any medium or format, as long as you give appropriate credit to the original author(s) and the source, provide a link to the Creative Commons licence, and indicate if changes were made. The images or other third party material in this article are included in the article's Creative Commons licence, unless indicated otherwise in a credit line to the material. If material is not included in the article's Creative Commons licence and your intended use is not permitted by statutory regulation or exceeds the permitted use, you will need to obtain permission directly from the copyright holder. To view a copy of this licence, visit http://creativeco mmons.org/licenses/by/4.0/. The Creative Commons Public Domain Dedication waiver (http://creativecommons.org/publicdomain/ zero/1.0/) applies to the data made available in this article, unless otherwise stated in a credit line to the data. 


\section{Background}

Visceral leishmaniasis (VL), a significantly neglected disease, is a systemic and chronic disease. Severe zoonosis occurs due to infections with Leishmania donovani or $L$. infantum. Worldwide, recurrent epidemics of VL have caused high morbidity and mortality in affected communities in 88 countries, with an estimated 400,000 new cases and 20,000 to 40,000 associated deaths [1]. VL is even now prevalent in China, in the Gansu, Sichuan, Qinghai and Shanxi Provinces and the Xinjiang Uygur Autonomous Region [2]. Pentavalent antimonials $\left(\mathrm{Sb}^{\mathrm{V}}\right)$ have been used as a first choice of treatment for VL in China, but currently the development of resistance against antimonials has become serious, and the severe effects of sodium stibogluconate, another anti-leishmanial drug, on the heart, liver and pancreas cannot be ignored [3]. Similar to antimonials, anti-Leishmanial drugs, such as amphotericin B, miltefosine and pentamidine, are also associated with severe side effects and resistance due to their long half-lives [4]. Thus, new therapeutic drugs are urgently needed.

It has always been controversial whether the immunosuppressor cyclosporin A (CsA) and its non-immunosuppressive derivatives can be used to treat VL. CsA displays anti-microbial activity against a variety of protozoan pathogens, such as Toxoplasma and Trypanosoma brucei $[5,6]$. CsA has also been employed to inhibit Leishmania species. Previous studies have suggested that CsA has damaging effects on Leishmania tropica [7, 8] and L. major [9] in vivo and extracellular promastigotes of L. tropica were found to be sensitive to CsA [10]. Meanwhile, CsA was found to have a dosedependent inhibitory effect on the growth of both $L$. donovani promastigotes and axenic amastigotes [11]. In addition, CsA was found to have a desired effect on VL in clinical cases [12]. It was considered to be highly efficacious in treating cytophagic histiocytic panniculitis and haemophagocytic lymphohistiocytosis, triggered by a previous visceral Leishmania infection, after failure of treatment with drugs, such as high-dose glucocorticoids, anakinra and etoposide [12]. However, CsA treatment was observed to convert the $L$. donovani-infected "cure" C57BL/10 mouse phenotype to a "noncure" phenotype [13]. Further, these mice exhibited a significant increase in the level of infection after 15 days of CsA-treatment [14], and the number of infected macrophages and amastigotes per macrophage in CsA-treated mice was significantly increased [15]. Based on these controversial results, we thought that CsA might inhibit the viability and proliferation of Leishmania promastigotes and host-free amastigotes in vitro and that CsA would likely play a prominent role in leishmanial infection in animals. Therefore, we hypothesized that the effect of CsA inhibition on intracellular amastigotes of $L$. donovani is counteracted by its immunosuppressive effect.

CsA exhibits its immunosuppressive action by inhibiting the production of calcineurin through binding to its intracellular specific receptor, cyclophilin A (CyPA) [16, 17]. Leishmania donovani can also express a variant of CyPA, known as $L$. donovani cyclophilin A ( $L d$ CyPA) $[18,19]$, whose structural and biological functions are different from those of human CyPA. LdCyPA was shown to play a pivotal role in the survival and persistence of parasites in infected tissues [20]. Thus, the inhibitory efficacy of CsA towards intracellular amastigotes can be indirectly verified by changes in the expression levels of CyPA and $L d$ CyPA.

Dihydrocyclosporin A (DHCsA-d), which is a closely related co-metabolite of CsA [21], has been reported to exert only marginal immunosuppressive activity and has been used as a control to determine the role of immunosuppression in the pharmacology of CsA-based treatment of parasitic infections [22]. Interestingly, DHCsA-d was found to also inhibit parasites in vivo and in vitro [22]. Therefore, we aimed to explore whether DHCsA-d could be used as an inhibitor of $L$. donovani.

In this study, promastigotes and intracellular amastigotes were subjected to treatment with CsA, DHCsA-d, or sodium stibogluconate (SSG) to find their effective 50\% inhibitory concentrations. Next, changes in the morphology and ultrastructure of $L$. donovani promastigotes and intracellular amastigotes were assessed and cytokine and nitric oxide $(\mathrm{NO}) /$ hydrogen peroxide $\left(\mathrm{H}_{2} \mathrm{O}_{2}\right)$ production by the cells was detected after CsA, DHCsA-d, or SSG treatment. Finally, the expression of $L d C y \mathrm{PA}$ in promastigotes and intracellular amastigotes and the expression of CyPA in RAW 264.7 cells that were cultured in the presence of CsA, DHCsA-d, or SSG were detected using western blotting to verify the efficacy of DHCsA-d and CsA against $L$. donovani promastigotes, intracellular amastigotes and cells.

\section{Methods \\ Parasite strains}

Leishmania donovani strain MHOM/CN/IN/80/DD8 was used in this study [23]. Leishmania promastigotes in the logarithmic phase were cultured at $28{ }^{\circ} \mathrm{C}$ in M199 medium at pH 7.4 (Sigma-Aldrich, Saint Louis, MO, USA), supplemented with $10 \%$ fetal bovine serum (Hyclone, Logan, UT, USA) and antibiotics (Pen-Strep, $100 \mathrm{U} / \mathrm{ml}$ penicillin-100 $\mu \mathrm{M}$ streptomycin sulphate).

\section{Drugs}

Stibogluconate sodium (MCE, Monmouth Junction, NJ, USA) was dissolved in saline to prepare a $20 \mathrm{mM}$ stock. Cyclosporin A (ApexBio, Houston, TX, USA) 
and dihydrocyclosporin A (TRC, North York, ON, CA) were dissolved in a $20 \mathrm{mM}$ stock of dimethyl sulfoxide (DMSO) (Sigma-Aldrich). For experiments, the DMSO concentration in the culture medium did not exceed $0.1 \%$.

\section{In vitro inhibitory assays}

Promastigotes, in logarithmic phase, were grown at a cell density of $1.0 \times 10^{6}$ cells $/ \mathrm{ml}$, CsA, DHCsA-d, or SSG was added at different concentrations prepared from concentrated stock solutions: $5,10,15,20$ and $25 \mu \mathrm{M}$ for CsA [11]; 5, 10, 15, 20 and $25 \mu \mathrm{M}$ for DHCsA-d [22]; and 5, 10, 25, 50 and $90 \mu \mathrm{M}$ for SSG [24]. Parasite inhibition rates were evaluated at $24 \mathrm{~h}$ and $48 \mathrm{~h}$ using flow cytometry, employing an FITC Annexin V Apoptosis Detection Kit I (BD, Franklin Lakes, NJ, USA), according to the manufacturer's instructions. Inhibition rate (\%) was calculated as follows: Inhibition rate $(\%)=100 \%-[$ (No. of live parasites in treated sample/No. of live parasites in untreated control) $\times 100 \%]$.

To evaluate the inhibitory effects of CsA, DHCsA-d, or SSG on intracellular amastigotes, we infected macrophages of a murine macrophage stable cell line (RAW 264.7) (Jennio, Guangzhou, China) with logarithmic phase promastigotes. RAW 264.7 cells $\left(5.0 \times 10^{5}\right.$ cells/ per well) were plated on round glass coverslips in 24-well plates and allowed to adhere to the slides for $24 \mathrm{~h}$ at $37{ }^{\circ} \mathrm{C}, 5 \% \mathrm{CO}_{2}$, in PRMI 1640 medium (Gibco, Franklin, TN, USA) supplemented with $10 \%$ FBS (Gibco). Adherent macrophages were infected with $L$. donovani promastigotes, at a macrophages-to-parasite ratio of 1:20 for $6 \mathrm{~h}$ at $37^{\circ} \mathrm{C}, 5 \% \mathrm{CO}_{2}$. Next, the non-infected parasites were removed by washing three times with $\mathrm{PBS}$, and the infected macrophages were incubated in $37{ }^{\circ} \mathrm{C}$ in $5 \% \mathrm{CO}_{2}$ with PRMI 1640 medium and 10\% FBS without drugs for $24 \mathrm{~h}$. The medium was then removed and different concentrations of CsA $(3,6,10,15,20 \mu \mathrm{M})$, DHCsA-d (3, 6, $10,15,20 \mu \mathrm{M})$ or SSG $(5,10,25,50,90 \mu \mathrm{M})$ dissolved in fresh medium were added, and the coverslips were incubated for 2 days. At 24 and $48 \mathrm{~h}$, the glass coverslips were fixed in methanol (Solarbio, Beijing, China) and stained with Wright's stain (Solarbio). The numbers of parasites were determined using light microscopy by counting at least 200 cells per slide. The results are expressed as means of three independent experiments. The $50 \%$ inhibitory concentration $\left(\mathrm{IC}_{50}\right)$ was calculated for promastigotes and intracellular amastigotes by fitting the values to a non-linear curve analysis.

\section{Electron microscopy}

CsA, DHCsA-d, or SSG-treated control promastigotes and intracellular amastigotes within the macrophages of RAW 264.7 cell line were fixed in $2.5 \%$ glutaraldehyde in
$0.1 \mathrm{M}$ cacodylate buffer ( $\mathrm{pH} 7.2)$ and post-fixed in a solution containing $1 \% \mathrm{OsO}_{4}, 1.25 \%$ potassium ferrocyanide and $0.1 \mathrm{M}$ cacodylate buffer, $\mathrm{pH}$ 7.2. Next, the cells were dehydrated in acetone and embedded in epoxy resin. Stained with lead citrate and observed under a Hitachi HT7700 transmission electron microscope.

\section{Production of polyclonal antibody of $L d C y P A$ and western blotting}

Polyclonal antibodies against $L d \mathrm{CyPA}$ were obtained to monitor protein expression. Representative peptides of $L d C y P A$ were analyzed through two predictors for $\mathrm{B}$ cells, BEPIPRED and BCPRED12. Among these, 8 peptides were found to be highly immunogenic. The $L d$ CyPA gene was amplified by PCR (forward primer: 5'-CGC CGA ATT CAT GTC TTA CAC GCC GCA CTA CCC CG-3'; reverse primer: 5'-CCG GTC GAC TTA AAG CTG TCC GCA GGC AGC CAC G-3') and cloned into pET28a (Promega, Madison, WI, USA) for sequencing and expressing proteins. Polyclonal antiserum was produced in New Zealand white rabbits. The rabbits were immunized with Freund's adjuvant (Sigma-Aldrich), containing $1500 \mu \mathrm{g}$ of $L d C y P A$ peptide, on days 0,15 and 30. The rabbits received three subcutaneous injections, the first in complete Freund's adjuvant and later two in incomplete Freund's adjuvant. Serum was obtained and antibody titers were estimated by ELISA on 25 and 42 days after the last injection.

Promastigotes, intracellular amastigotes and RAW 264.7 cells were co-cultured with the three compounds, CsA, DHCsA-d, or SSG for $48 \mathrm{~h}$. Promastigotes were treated with CsA $(16 \mu \mathrm{M})$, DHCsA-d $(12 \mu \mathrm{M})$, or SSG $(20 \mu \mathrm{M})$; intracellular amastigotes and RAW 264.7 cells were treated with CsA $(10 \mu \mathrm{M})$, DHCsA-d $(5 \mu \mathrm{M})$, or SSG $(9 \mu \mathrm{M})$. These cells were then lysed with a protein lysis buffer supplemented with protease and phosphatase inhibitors and the protein concentration was determined by the BCA Kit (Beyotime). The extracted proteins were denatured for $5 \mathrm{~min}$ at $100{ }^{\circ} \mathrm{C}$ after adding appropriate amounts of loading buffer. Approximately 40 to $50 \mu \mathrm{g}$ of proteins was loaded in each lane of a $12 \%$ polyacrylamide gel (Beyotime). Proteins were separated at $120 \mathrm{~V}$ until the dye front reached the bottom of the gel, followed by transfer of the gels to polyvinylidene fluoride (PVDF) membranes (EMD, MA, USA) in transfer buffer ( $25 \mathrm{mM}$ Tris- $\mathrm{HCl}, 192 \mathrm{mM}$ glycine, 20\% methanol, 0.02\% SDS, pH 8.3 ) and run at $200 \mathrm{~mA}$ for $60 \mathrm{~min}$. The membranes were then soaked in a blocking buffer $(1 \times$ PBS, $0.1 \%$ Tween 20 ) and supplemented with $1 \%$ bovine serum albumin (Sigma-Aldrich) for $2 \mathrm{~h}$, before incubating overnight at $4{ }^{\circ} \mathrm{C}$ individually with $L d$ CyPA polyclonal antibody, CyPA antibody (Affinity, Dublin, OH, USA) and $\alpha$-tubulin antibody (Affinity) at appropriate dilutions. All the primary 
antibodies were used at a 1:4000 dilution and horseradish peroxidase-conjugated anti-rabbit immunoglobulin secondary antibodies (Affinity) were used at a 1:5000 dilution. The PVDF membranes were visualized with an enhanced chemiluminescence western blotting detection kit (Beyotime) and the protein bands were analyzed by densitometric studies using ImageJ software.

\section{Quantification of cytokines, $\mathrm{NO}$ and $\mathrm{H}_{\mathbf{2}} \mathrm{O}_{2}$}

Mouse RAW 264.7 macrophages $\left(5.0 \times 10^{5}\right.$ cells/per well), adhered for $24 \mathrm{~h}$ at $37{ }^{\circ} \mathrm{C}, 5 \% \mathrm{CO}_{2}$, in PRMI 1640 medium supplemented with $10 \%$ FBS were infected with promastigotes at a macrophages-to-parasite ratio of 1:20 for $6 \mathrm{~h}$ at $37^{\circ} \mathrm{C}, 5 \% \mathrm{CO}_{2}$, and subsequently the noninfected parasites were removed by washing three times with PBS. Infected macrophages were incubated in PRMI 1640 medium and $10 \% \mathrm{FBS}$ at $37{ }^{\circ} \mathrm{C}, 5 \% \mathrm{CO}_{2}$, without drugs for $24 \mathrm{~h}$. Next, the medium was removed and CsA $(10 \mu \mathrm{M})$, DHCsA-d $(5 \mu \mathrm{M})$, or SSG $(9 \mu \mathrm{M})$ (concentrations showing $\mathrm{IC}_{50}$ for intercellular amastigotes in this study) were added using fresh medium. The cells were further incubated for 3 days, and the medium supernatants were retrieved at 24,48 and $72 \mathrm{~h}$. Subsequently, the cytokines IL-12, IL-10, IL-4, IFN- $\gamma$ and TNF- $\alpha$ were measured utilizing the BD OpitELA ELISA Kit (BD). $\mathrm{NO}$ and $\mathrm{H}_{2} \mathrm{O}_{2}$ concentrations in the supernatants were detected by nitric oxide and hydrogen peroxide assay kits (Beyotime), respectively.

\section{Cytotoxicity assessment}

Cytotoxicity effects of CsA, DHCsA-d, or SSG against murine macrophages (RAW 264.7) were assessed by using the Cell Counting Kit-8 (KeyGEN, Shanghai, China). Murine macrophages were cultivated in a 96-well plate using PRIM 1640 medium containing 10\% FBS and maintained at $37{ }^{\circ} \mathrm{C}, 5 \% \mathrm{CO}_{2}$, for $24 \mathrm{~h}$. Next, different concentrations of the drugs $(7,10,20,50$ and $100 \mu \mathrm{M}$ for CsA and DHCsA-d; 60, 75, 90, 105 and $120 \mu \mathrm{M}$ for SSG) were added. The cytotoxicity was measured at 24 and $48 \mathrm{~h}$ following a standard protocol.

\section{Statistics}

All experiments were carried out in triplicates and repeated at least three times and the figures shown are representative of these experiments. $\mathrm{IC}_{50}$ were calculated according to a nonlinear regression using a log inhibitorversus response equation with $95 \%$ confidence intervals in the GraphPad Prism 6.0 software. The data were analyzed using Student's t-test for comparison of two groups and data values were expressed as the mean \pm standard deviation (SD). Significant differences were determined and designated with asterisks as follows: ${ }^{*} P<0.05$; ** $P<0.01$; **** $P<0.001$ and ${ }^{* * * * *} P<0.0001$.

\section{Results}

\section{Susceptibility testing}

We treated promastigotes with different concentrations of CsA, DHCsA-d, or SSG for 24 and $48 \mathrm{~h}$; this was followed by flow cytometry using annexin V-FITC and PI labeling. All the three drugs could inhibit promastigotes at $24 \mathrm{~h}$ (Fig. 1a) and their inhibitory effect was enhanced over a period of time (Fig. 1b). The inhibition rates were calculated (Fig. 1c, d). Intracellular amastigotes were treated with different concentrations of CsA, DHCsA-d, or SSG for 24 and $48 \mathrm{~h}$ followed by microscopy to calculate inhibition rates (Fig. 2i, j). The results of Wright's staining suggested that compared to the numbers of untreated amastigotes (Fig. 2a, b), the numbers of DHCsA-d-treated or SSG-treated intracellular amastigotes were reduced after $24 \mathrm{~h}$ of treatment (Fig. 2e, g) and were basically absent after $48 \mathrm{~h}$ of treatment (Fig. 2f, h), leaving several different sizes of parasitophorous vacuoles in the cells. Interestingly, on the contrary, the number of intracellular amastigotes was significantly increased in CsA-treated cells after a $24 \mathrm{~h}$ (Fig. 2c) and $48 \mathrm{~h}$ (Fig. 2d) treatment compared with that in the control group cells.

Based on the inhibitory effect of different concentrations of the drugs assessed, $\mathrm{IC}_{50}$ values of these three drugs were calculated (Table 1 ). The $\mathrm{IC}_{50}$ values of DHCsA-d-treated promastigotes were $21.24 \mu \mathrm{M}(24 \mathrm{~h})$ and $12.14 \mu \mathrm{M}(48 \mathrm{~h})$. Likewise, DHCsA-d had a striking inhibitory effect on the growth of intercellular amastigotes. The $\mathrm{IC}_{50}$ values of DHCsA-d-treated amastigotes were $5.23 \mu \mathrm{M}$ and $4.84 \mu \mathrm{M}$ at 24 and $48 \mathrm{~h}$, respectively. CsA was also active against promastigotes, showing an $\mathrm{IC}_{50}$ value of $23.44 \mu \mathrm{M}$ at $24 \mathrm{~h}$ and $15.88 \mu \mathrm{M}$ at $48 \mathrm{~h}$. The $\mathrm{IC}_{50}$ value of CsA towards intercellular amastigotes was not determined because we found that the number of amastigotes in the CsA-treated group was increased compared with that in the control group. The SSG group showed $\mathrm{IC}_{50}$ values of $32.33 \mu \mathrm{M}(24 \mathrm{~h})$ and $20.23 \mu \mathrm{M}(48 \mathrm{~h})$ for promastigotes and $9.51 \mu \mathrm{M}(24 \mathrm{~h})$ and $8.27 \mu \mathrm{M}(48 \mathrm{~h})$ for amastigotes.

\section{Drugs altered mitochondrial ultrastructure}

CsA, DHCsA-d, or SSG induced significant morphological changes in promastigotes, including increased aggregate formation, oval cell shape and shortened and motionless flagellae (Fig. 3b-d). The ultrastructure of the main organelles of $L$. donovani was also significantly altered after treatment with CsA, DHCsA-d, or SSG, especially that of the mitochondria, which appeared completely disorganized (Fig. 3b-d). As shown in Fig. 3a, the control promastigotes presented normal ultrastructure for mitochondria and nuclei. Moreover, there was an abnormal increase in the number of flagellae in DHCsA-d-treated promastigotes (Fig. 3c). 
The untreated intracellular amastigotes presented normal ultrastructure for nuclei and mitochondria (Fig. 4a). The mitochondria of intracellular amastigotes treated with DHCsA-d or SSG appeared disintegrated (Fig. 4c, d). Almost half of the DHCsA-d-treated intracellular amastigotes were degraded in parasitophorous vacuoles (Fig. 4c). CsA-treated intracellular amastigotes remained unchanged, unlike the CsA-treated promastigotes, which did not show significant changes as compared to the untreated group (Fig. 4b).

The effect of CsA, DHCsA-d, or SSG on cytokine, $\mathrm{NO}$ and $\mathrm{H}_{2} \mathrm{O}_{2}$ production

CsA, DHCsA-d, or SSG were incubated with L. donovani non-infected and infected macrophages. The supernatants of the medium were assayed to quantify pro-inflammatory cytokines (IL-12, IFN- $\gamma$ and TNF$\alpha$ ), which are crucial for the successful treatment of VL and anti-inflammatory cytokines (IL-10 and IL-4), which participate in the exacerbation of the disease. The levels of cytokines were evaluated by ELISA. IL-12, IFN- $\gamma$ and TNF- $\alpha$ all showed significant downregulation after infection (Fig. 5a-c). Leishmania donovani are found to be sensitive to DHCsA-d and SSG, thus the DHCsA$\mathrm{d}$ and SSG treatments resulted in significant increases of IL-12, IFN- $\gamma$ and TNF- $\alpha$ in L. donovani infected cells on the $24 \mathrm{~h}, 48 \mathrm{~h}$ and $72 \mathrm{~h}$. However, the levels of these three cytokines did not change significantly in $L$.
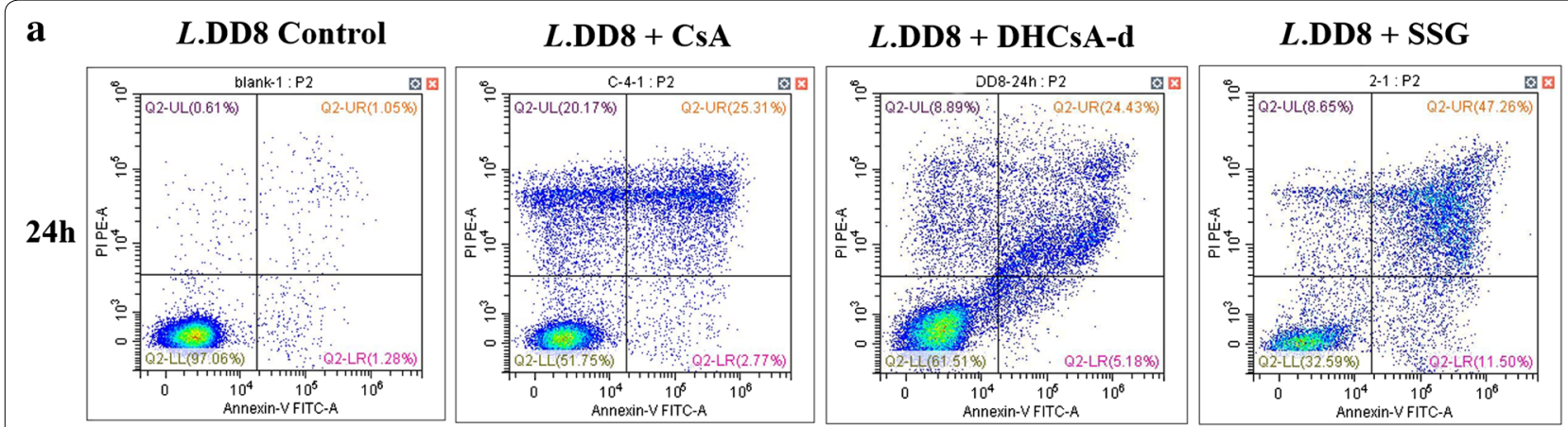

b

L.DD8 Control
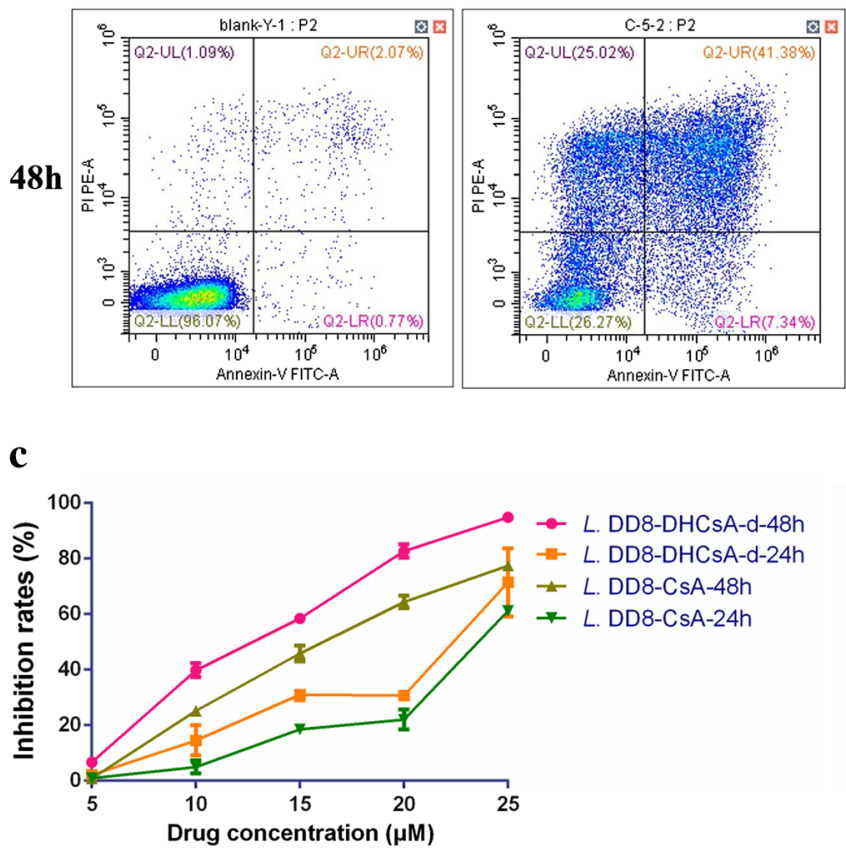

L.DD8 + DHCsA-d

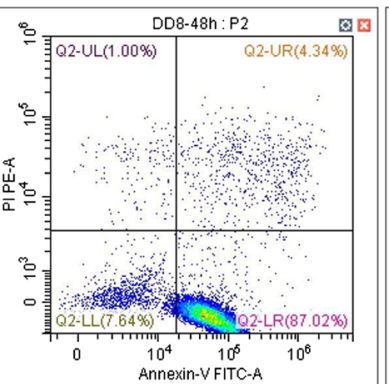

d

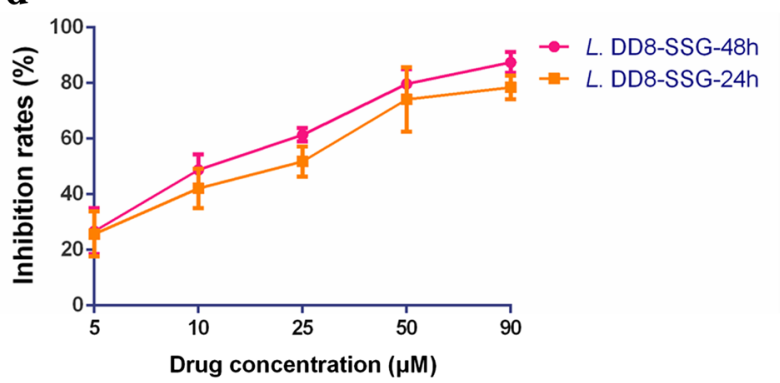

Fig. 1 CSA, DHCSA-d, or SSG treatment affects promastigotes multiplication and inhibition rates of promastigotes. Live promastigotes (LL quadrant) were assayed by flow cytometry at $24 \mathrm{~h}$ (a) or $48 \mathrm{~h}(\mathbf{b})$ after treatment with the individual drugs. $\mathbf{c}$ Inhibition rates of promastigotes treated with different concentration of CSA and DHCSA-d at $24 \mathrm{~h}$ and $48 \mathrm{~h}$. $\mathbf{d}$ Inhibition rates of promastigotes treated with different concentration of SSG at $24 \mathrm{~h}$ and $48 \mathrm{~h}$ 
donovani-infected cells in the CsA-treated group compared to those in the untreated group.

The tendencies of variation of the cytokines IL-10 and IL-4 and $\mathrm{NO}$ and $\mathrm{H}_{2} \mathrm{O}_{2}$ production were identical. IL-10, IL-4, NO and $\mathrm{H}_{2} \mathrm{O}_{2}$ production showed significant enhancement after infection (Fig. $5 \mathrm{~d}-\mathrm{g}$ ) but was observed to be significantly decreased in DHCSA-d and SSG- treated L. donovani at $24 \mathrm{~h}, 48 \mathrm{~h}$ and $72 \mathrm{~h}$. However, the levels of IL-10, IL-4, NO and $\mathrm{H}_{2} \mathrm{O}_{2}$ did not change significantly in $L$. donovani infected cells in the CsAtreated group compared to those in the untreated group. Furthermore, the levels of all the five cytokines and NO and $\mathrm{H}_{2} \mathrm{O}_{2}$ production decreased over a period of time in all groups after treatment. The results of statistical tests were calculated (Table 2).

\section{Preparation of $L d C y P A$ antibody}

The LdCyPA gene was successfully amplified by PCR and ligated into the plasmid pET-28a. The construction of the recombinant plasmid was verified by double enzyme digestion. The recombinant pET-28a vector was then transferred into BL21 cells to express the fusion protein, which was purified using Ni-NTA agarose affinity chromatography and verified by the sodium dodecyl sulfate polyacrylamide gel electrophoresis (Fig. 6a, b). Further, western blotting demonstrated that a purified $L d C y P A$

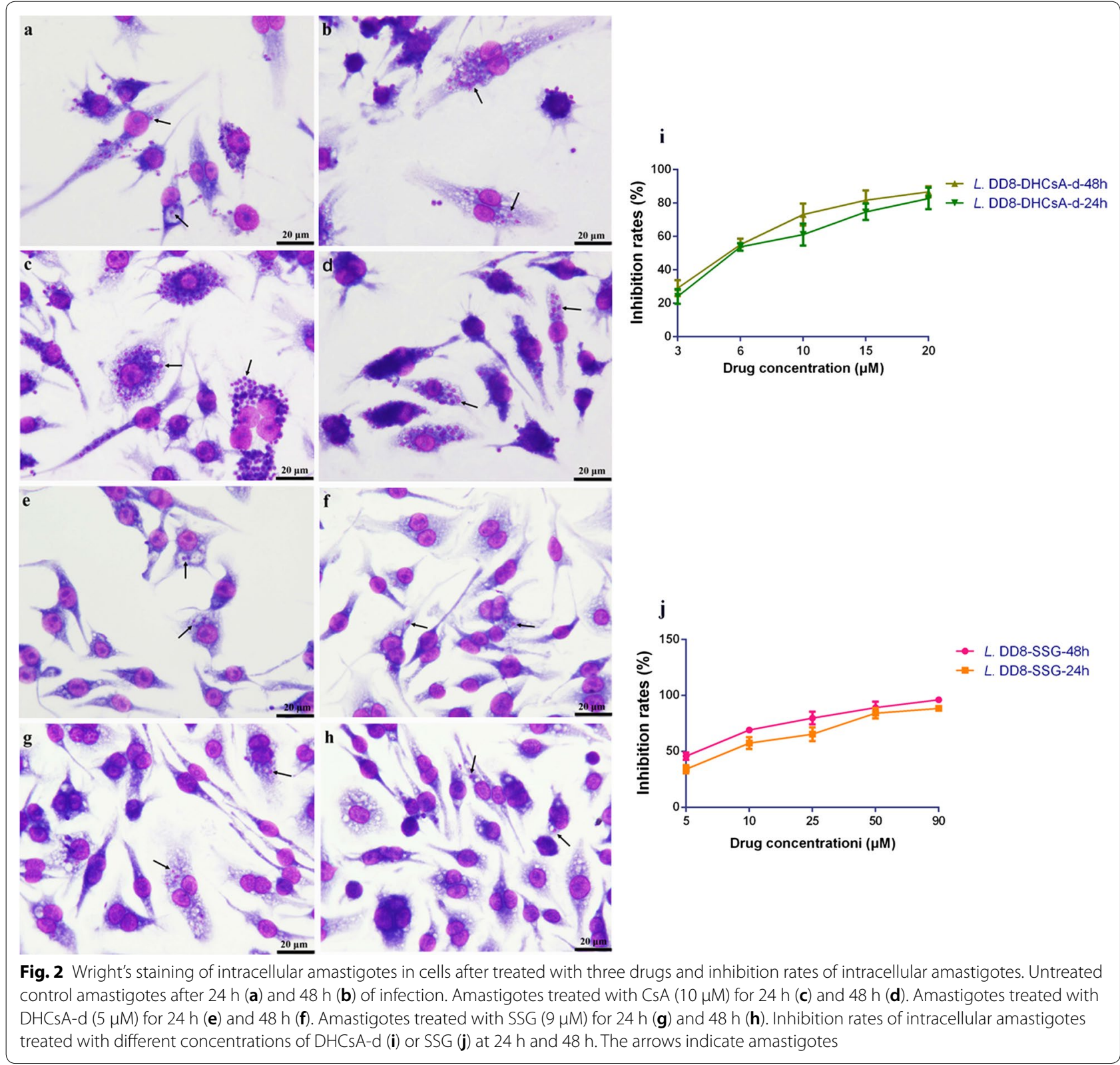


Table $1 \quad I_{50}$ of CsA, DHCsA-d, or SSG used for treatment of leishmanial promastigotes and intracellular amastigotes

\begin{tabular}{|c|c|c|c|c|}
\hline \multirow[t]{3}{*}{ Compound } & \multicolumn{2}{|l|}{ Promastigotes $I C_{50}$} & \multicolumn{2}{|l|}{ Amastigotes $I C_{50}$} \\
\hline & $24 \mathrm{~h}$ & $48 \mathrm{~h}$ & $24 \mathrm{~h}$ & $48 \mathrm{~h}$ \\
\hline & Mean $\pm S D(\mu M)$ & Mean $\pm S D(\mu M)$ & Mean $\pm S D(\mu M)$ & Mean $\pm S D(\mu M)$ \\
\hline CsA & $23.44 \pm 0.3$ & $15.88 \pm 0.4$ & nd & nd \\
\hline DHCsA-d & $21.24 \pm 1.2$ & $12.14 \pm 1.1$ & $5.23 \pm 2.1$ & $4.84 \pm 0.4$ \\
\hline SSG & $32.33 \pm 1.6$ & $20.23 \pm 1.4$ & $9.51 \pm 0.5$ & $8.27 \pm 0.1$ \\
\hline
\end{tabular}

Note: Data are represented as the mean \pm SD of three independent experiments

Abbreviations: $\mathrm{IC}_{50}, 50 \%$ inhibitory concentration; nd, not determined; $\mathrm{SD}$, standard deviation

protein was obtained (Fig. 6c). The concentration of the $L d$ CyPA protein was $3.87 \mathrm{mg} / \mathrm{ml}$, as estimated by the BCA method. Serum samples of rabbits immunized with LdCyPA were collected for detection of the titers on 25 and 42 days. Since the titers were greater than 1:50,000 according to ELISA, the sera of these rabbits were further purified to obtain specific $L d C y P A$ antibodies.

\section{The expression of CyPA and $L d C y P A$ after drug inhibition}

The expression of $L d C y P A$ in promastigotes $\left(t_{(4)}=11.45\right.$, $P=0.0003)$ and intracellular amastigotes $\left(t_{(4)}=18.85\right.$,
$P<0.0001)$ treated with CsA and the expression of CyPA in RAW 264.7 cells $\left(t_{(4)}=12.95, P=0.0002\right)$ treated with CsA were found to be significantly downregulated compared to those in the untreated cells (Fig. 7a-f). However, no significant changes were found in the expression levels of $L d$ CyPA in promastigotes $\left(t_{(4)}=2.076, P=0.1065\right.$; $\left.t_{(4)}=1.45, \quad P=0.2206\right)$ and intracellular amastigotes $\left(t_{(4)}=0.1112, \quad P=0.9168 ; t_{(4)}=1.131, \quad P=0.3213\right)$ and CyPA in RAW 264.7 cells $\left(t_{(4)}=1.862, P=0.1361\right.$; $\left.t_{(4)}=0.2635, P=0.8052\right)$ treated with DHCsA-d or SSG compared to those in the untreated cells (Fig. $7 \mathrm{a}-\mathrm{f}$ ).

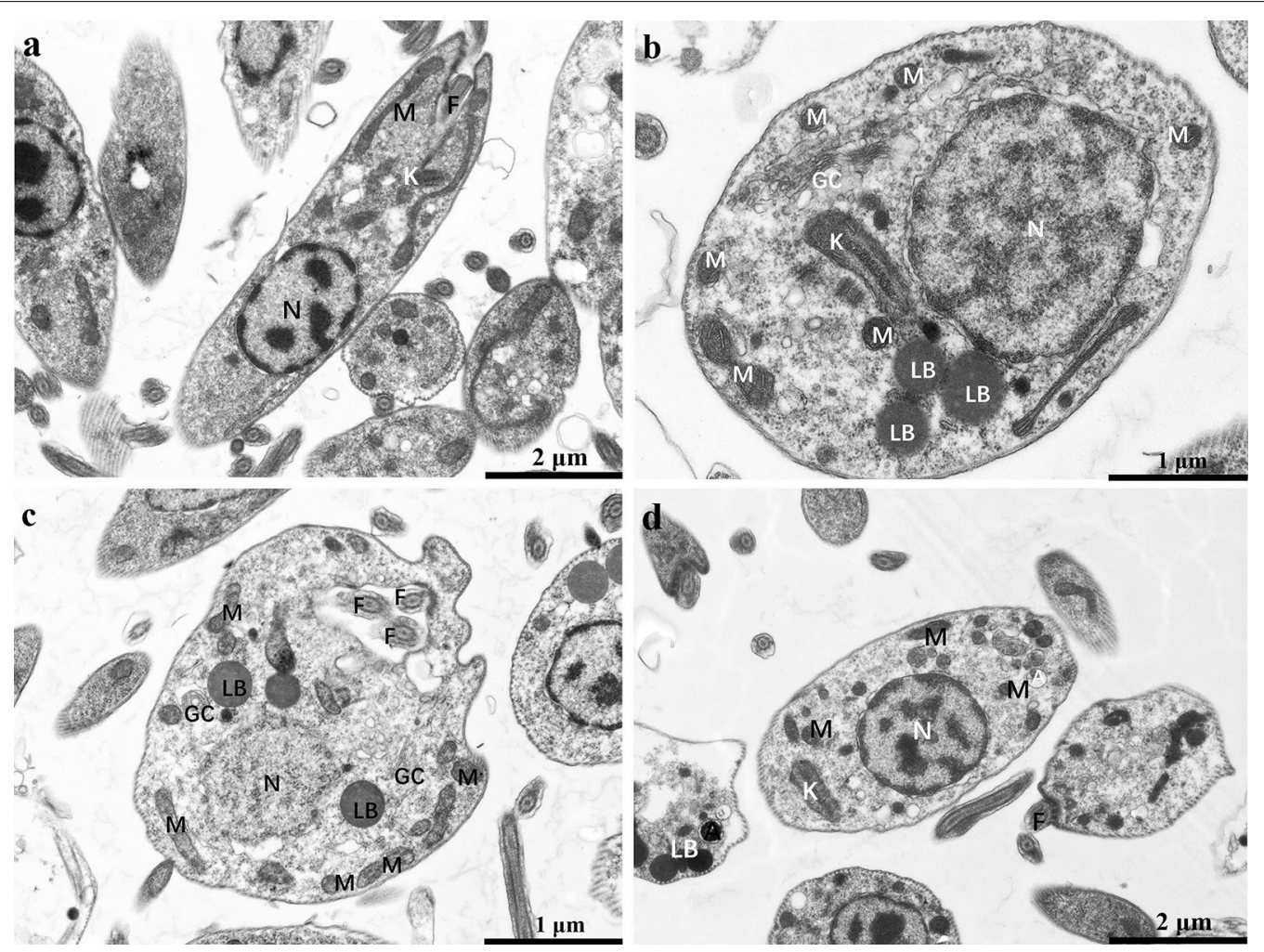

Fig. 3 Ultrathin sections of promastigotes. Untreated control promastigotes (a) and promastigotes treated with CsA (16 $4 \mathrm{M})(\mathbf{b}), \mathrm{DHCsA}-\mathrm{d}(12 \mu \mathrm{M})$ (c), or SSG $(20 \mu \mathrm{M})$ (d) for $48 \mathrm{~h}$. There were several alterations observed, such as changes in the shape of the promastigotes and mitochondria (b-d): the promastigotes became rounded and mitochondria became rounded and swollen and several lipid bodies were present $(\mathbf{b}, \mathbf{c})$ and multiple flagellum (c). Abbreviations: F, flagellum; GC, Golgi complex; K, kinetoplast; LB, lipid bodies; M, mitochondrion; N, nucleus 
Densitometric analysis results showed lower $L d \mathrm{CyPA}$ levels in promastigotes and amastigotes treated with CsA than in those treated with DHCsA-d or SSG (Fig. 7d, e) and lower CyPA levels were seen in RAW 264.7 cell cocultured with CsA than those co-cultured with DHCsA-d or SSG (Fig. 7f).

\section{Dihydrocyclosporin A induced high cytotoxicity in RAW264.7 cells}

The safety profile of CsA, DHCsA-d, or SSG was examined using a mammalian cytotoxicity test using RAW 264.7 cells. CsA and DHCsA-d demonstrated cytotoxicity towards macrophages, showing $50 \%$ cytotoxic concentration $\left(\mathrm{CC}_{50}\right)$ values of $15.91 \mu \mathrm{M}(\mathrm{CsA}, 24 \mathrm{~h}), 12.65 \mu \mathrm{M}$ (CsA, $48 \mathrm{~h}$ ), $7.98 \mu \mathrm{M}$ (DHCsA-d, $24 \mathrm{~h}$ ) and $6.65 \mu \mathrm{M}$ (DHCsA-d, $48 \mathrm{~h}$ ); by contrast, SSG exhibited a $\mathrm{CC}_{50}$ value $>120 \mu \mathrm{M}$ (Table 3 ).

\section{Discussion}

VL is potentially fatal to patients if left untreated. Because it causes severe immunosuppression, it makes patients more susceptible to secondary microbial infections [25]. Due to the drug resistance, high cost, toxic side effects, and lengthy treatment regimens of pentavalent antimonials, it is necessary to find an alternative therapeutic drug for VL. As mentioned above, CsA and its non-immunosuppressive derivatives were considered to be potential therapeutic drugs to treat VL. However, whether CsA and its derivatives can be used as therapeutic drugs for VL has been controversial for many years.

In this study, the inhibitory effects of CsA and its derivative DHCsA-d on promastigotes and intracellular amastigotes of $L$. donovani were assessed. The number of intracellular amastigotes decreased significantly compared to that in the untreated group after administration of DHCsA-d or SSG. However, the number of intracellular amastigotes distinctly increased after the administration of CsA. These results indicated that CsA and DHCsA-d had anti-leishmanial effects on promastigotes, while CsA was found to promote the infection of intracellular amastigotes.

The role of CsA in promoting intracellular amastigote infection was confirmed by assessing morphological observation and cytokine expression levels in this study. According to ultrastructure observations, after treatment with DHCsA-d or SSG, there were obvious changes in
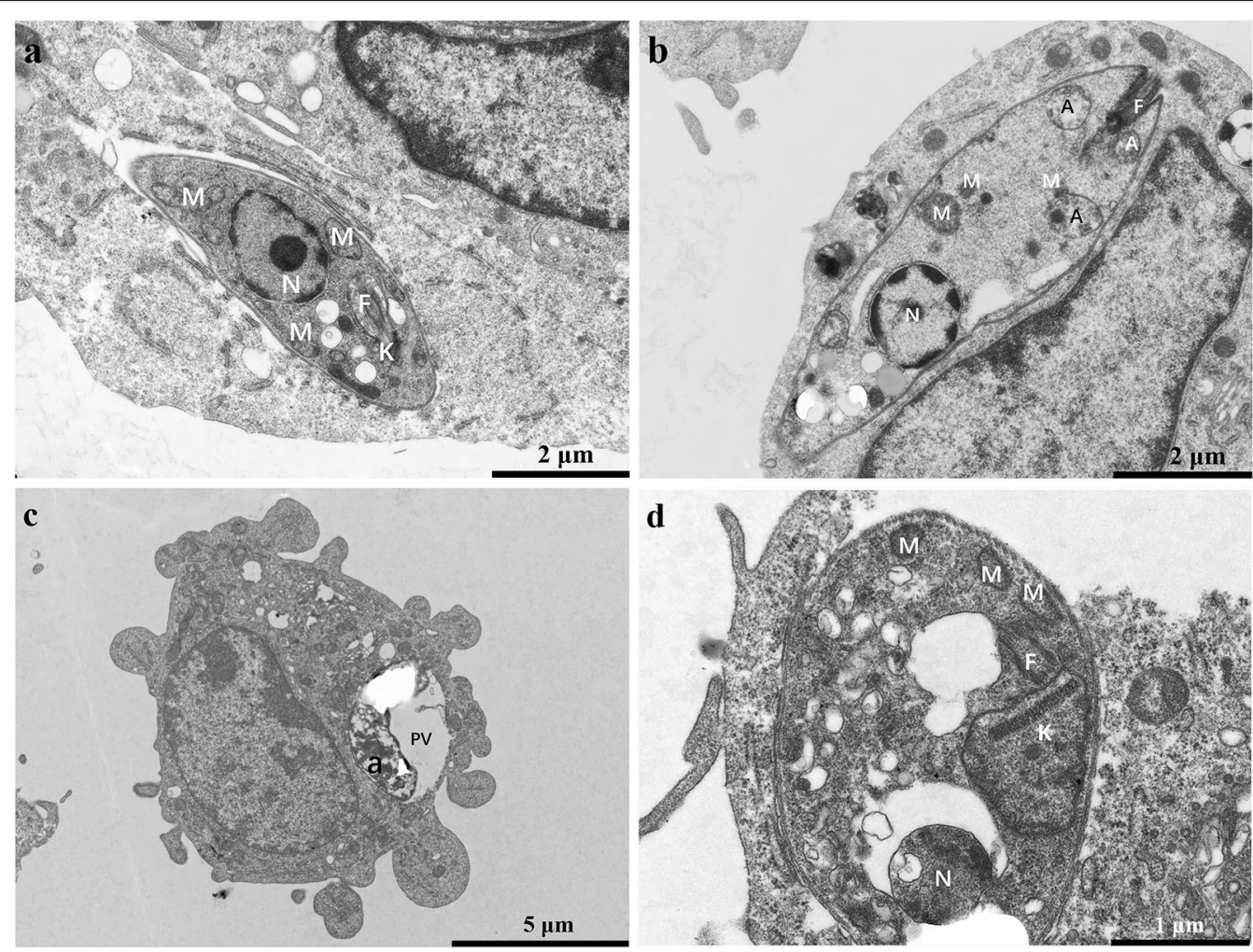

Fig. 4 Ultrathin sections of amastigotes. Untreated control amastigote (a) and amastigotes treated with CsA (10 $\mu M)(\mathbf{b}), \mathrm{DHCsA}-\mathrm{d}(5 \mu \mathrm{M})(\mathbf{c})$, or SSG $(9 \mu \mathrm{M})(\mathbf{d})$ for $48 \mathrm{~h}$. Several different ultrastructural alterations were observed, such as autophagosomes (b) in the cytoplasm; intense disorganization and swelling can be observed in nuclei of the parasites (d), degraded amastigotes in large parasitophorous vacuoles were observed (c). Abbreviations: a, amastigote; A, autophagosome; F, flagellum; K, kineplast; M, mitochondrion; N, nucleus; PV, parasitophorous vacuole 

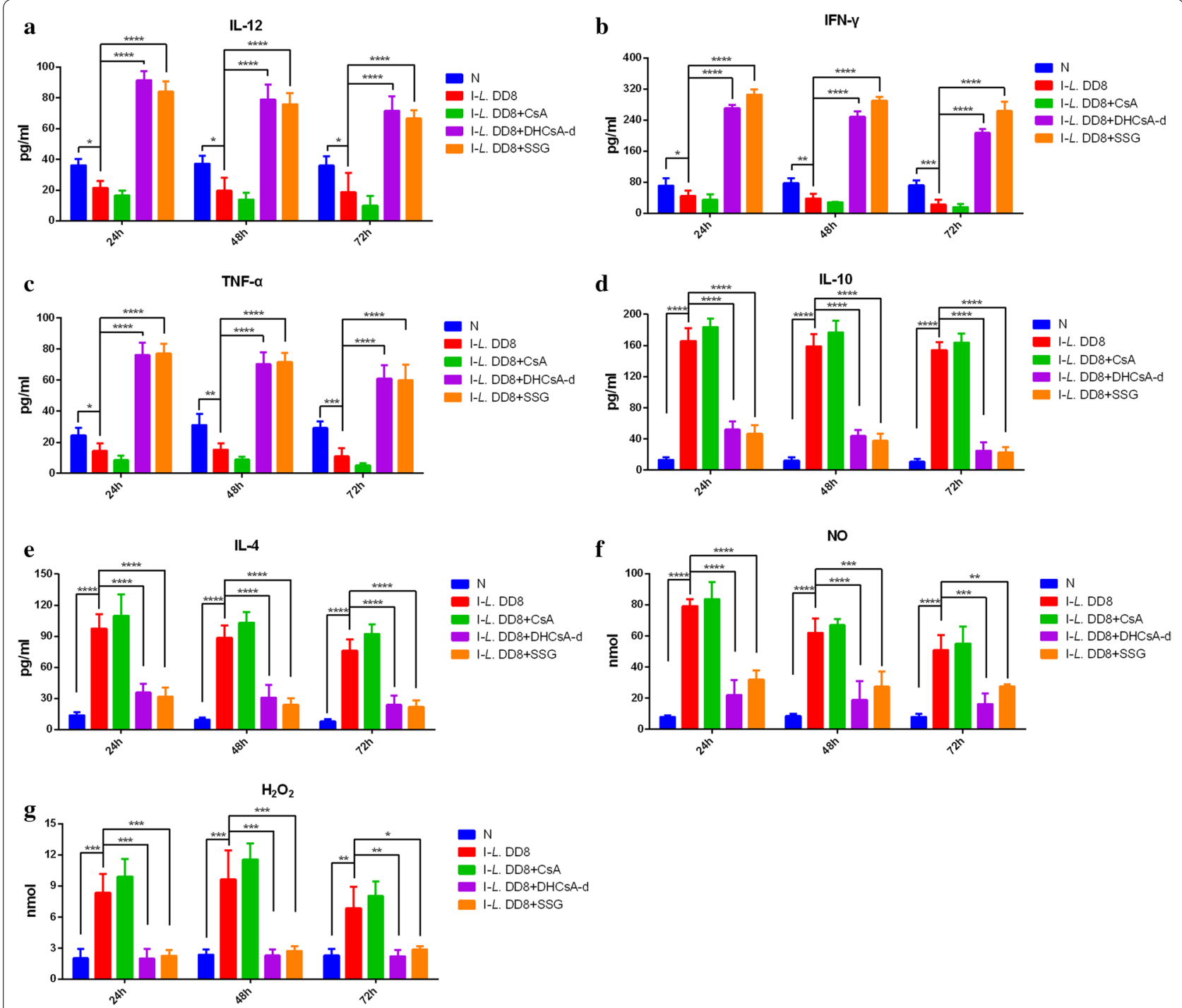

Fig. 5 Estimation of cytokines, $\mathrm{NO}$ and $\mathrm{H}_{2} \mathrm{O}_{2}$ in culture supernatants of RAW 264.7 by ELISA. Levels of interleukin 12 (IL-12) (a), interferon $\gamma$ (IFN- $\gamma$ ) (b), tumor necrosis factor a (TNF-a) (c), interleukin 10 (IL-10) (d), interleukin 4 (IL-4) (e), nitric oxide (NO) (f) and hydrogen peroxide $\left(\mathrm{H}_{2} \mathrm{O}_{2}\right)(\mathbf{g})$ production in culture supernatants was measured. Abbreviations: $N$, non-infected macrophages; I-L. DD8, macrophages infected with L. DD8; I-L. DD8 + SSG, SSG adding after macrophages infected with L. DD8; I-L. DD8 + CSA, CSA adding after macrophages infected with L. DD8; I-L. DD8 + DHCsA-d, DHCsA-d adding after macrophages infected with L. DD8. Data are the mean \pm standard error of the mean and represent the values of one of the 3 independent experiments. ${ }^{*} P<0.05$, ${ }^{* *} P<0.01$, ${ }^{* * *} P<0.001,{ }^{* * *} P<0.0001$

the mitochondria of promastigotes and amastigotes. The mitochondria were completely disorganized; this result was similar to the findings regarding ultrastructural changes in the mitochondria of L. amazonensis treated with itraconazole and ravuconazole [26, 27]. However, no obvious changes in mitochondria were observed after treatment with CsA.

Appropriate activation of macrophages, which are the major effector cells responsible for elimination of leishmania, is crucial for eliminating intracellular Leishmania [28]. Therefore, the effects of three pro-inflammatory cytokines (IL-12, IFN- $\gamma$ and TNF$\alpha$ ), which are crucial for the successful treatment of VL and anti-inflammatory cytokines (IL-4 and IL-10), which participate in the exacerbation of the disease, secreted by macrophages, were evaluated by ELISA in this study. We found that the levels of IL-4 and IL-10 were significantly increased, while those of IL-12, IFN- $\gamma$ and TNF- $\alpha$ were significantly decreased after phagocytosis of $L$. donovani by macrophages. These results are supported by the cytokine expression in VL patients who were infected with $L$. donovani [29]. High levels 
Table 2 Statistical tests for cytokines, $\mathrm{NO}$ and $\mathrm{H}_{2} \mathrm{O}_{2}$

\begin{tabular}{|c|c|c|c|c|}
\hline & & $24 \mathrm{~h}$ & $48 \mathrm{~h}$ & $72 \mathrm{~h}$ \\
\hline \multirow[t]{4}{*}{$\mid \mathrm{L}-12$} & N vs I-L. DD8 & $\begin{array}{l}t_{(12)}=2.4285 \\
P=0.0318\end{array}$ & $\begin{array}{l}t_{(12)}=2.9252 \\
P=0.0127\end{array}$ & $\begin{array}{l}t_{(12)}=2.87 \\
P=0.0141\end{array}$ \\
\hline & I-L. DD8 + CsA vs I-L. DD8 & $\begin{array}{l}t_{(12)}=0.8554 \\
P=0.4149\end{array}$ & $\begin{array}{l}t_{(12)}=0.9571 \\
P=0.3567\end{array}$ & $\begin{array}{l}t_{(12)}=1.4637 \\
P=0.1689\end{array}$ \\
\hline & I-L. DD8 + DHCsA-d vs I-L. DD8 & $\begin{array}{l}t_{(12)}=9.7045 \\
P<0.0001\end{array}$ & $\begin{array}{l}t_{(12)}=8.2368 \\
P<0.0001\end{array}$ & $\begin{array}{l}t_{(12)}=7.3545 \\
P<0.0001\end{array}$ \\
\hline & I-L. DD8 + SSG vs I-L. DD8 & $\begin{array}{l}t_{(12)}=9.6968 \\
P<0.0001\end{array}$ & $\begin{array}{l}t_{(12)}=8.7509 \\
P<0.0001\end{array}$ & $\begin{array}{l}t_{(12)}=7.4532 \\
P<0.0001\end{array}$ \\
\hline \multirow[t]{4}{*}{ IFN-y } & N vs I-L. DD8 & $\begin{array}{l}t_{(12)}=2.3545 \\
P=0.0364\end{array}$ & $\begin{array}{l}t_{(12)}=3.5317 \\
P=0.0041\end{array}$ & $\begin{array}{l}t_{(12)}=4.4146 \\
P=0.0008\end{array}$ \\
\hline & I-L. DD8 + CsA vs I-L. DD8 & $\begin{array}{l}t_{(12)}=1.0839 \\
P=0.2997\end{array}$ & $\begin{array}{l}t_{(12)}=1.0695 \\
P=0.3059\end{array}$ & $\begin{array}{l}t_{(12)}=0.7226 \\
P=0.4838\end{array}$ \\
\hline & I-L. DD8 + DHCsA-d vs I-L. DD8 & $\begin{array}{l}t_{(12)}=23.9059 \\
P<0.0001\end{array}$ & $\begin{array}{l}t_{(12)}=22.2593 \\
P<0.0001\end{array}$ & $\begin{array}{l}t_{(12)}=19.4494 \\
P<0.0001\end{array}$ \\
\hline & I-L. DD8 + SSG vs I-L. DD8 & $\begin{array}{l}t_{(12)}=21.4421 \\
P<0.0001\end{array}$ & $\begin{array}{l}t_{(12)}=20.7228 \\
P<0.0001\end{array}$ & $\begin{array}{l}t_{(12)}=19.7626 \\
P<0.0001)\end{array}$ \\
\hline \multirow[t]{4}{*}{ TNF-a } & N vs I-L. DD8 & $\begin{array}{l}t_{(12)}=2.3822 \\
P=0.0346\end{array}$ & $\begin{array}{l}t_{(12)}=3.8117 \\
P=0.0025\end{array}$ & $\begin{array}{l}t_{(12)}=4.3674 \\
P=0.0009\end{array}$ \\
\hline & I-L. DD8 + CsA vs I-L. DD8 & $\begin{array}{l}t_{(12)}=2.0144 \\
P=0.0669\end{array}$ & $\begin{array}{l}t_{(12)}=2.1263 \\
P=0.0549\end{array}$ & $\begin{array}{l}t_{(12)}=1.9025 \\
P=0.0814\end{array}$ \\
\hline & I-L. DD8 + DHCsA-d vs I-L. DD8 & $\begin{array}{l}t_{(12)}=11.3431 \\
P<0.0001\end{array}$ & $\begin{array}{l}t_{(12)}=10.1318 \\
P<0.0001\end{array}$ & $\begin{array}{l}t_{(12)}=9.2065 \\
P<0.0001\end{array}$ \\
\hline & I-L. DD8 + SSG vs I-L. DD8 & $\begin{array}{l}t_{(12)}=12.1475 \\
P<0.0001\end{array}$ & $\begin{array}{l}t_{(12)}=10.9044 \\
P<0.0001\end{array}$ & $\begin{array}{l}t_{(12)}=9.4807 \\
P<0.0001\end{array}$ \\
\hline \multirow[t]{4}{*}{ IL-10 } & N vs I-L. DD8 & $\begin{array}{l}t_{(12)}=17.7485 \\
P<0.0001\end{array}$ & $\begin{array}{l}t_{(12)}=17.021 \\
P<0.0001\end{array}$ & $\begin{array}{l}t_{(12)}=16.7054 \\
P<0.0001\end{array}$ \\
\hline & I-L. DD8 + CsA vs I-L. DD8 & $\begin{array}{l}t_{(12)}=1.6069 \\
P=0.134\end{array}$ & $\begin{array}{l}t_{(12)}=1.6572 \\
P=0.1234\end{array}$ & $\begin{array}{l}t_{(12)}=0.8703 \\
P=0.4012\end{array}$ \\
\hline & I-L. DD8 + DHCsA-d vs I-L. DD8 & $\begin{array}{l}t_{(12)}=11.2823 \\
P<0.0001\end{array}$ & $\begin{array}{l}t_{(12)}=11.3959 \\
P<0.0001\end{array}$ & $\begin{array}{l}t_{(12)}=12.8072 \\
P<0.0001\end{array}$ \\
\hline & I-L. DD8 + SSG vs I-L. DD8 & $\begin{array}{l}t_{(12)}=11.9725 \\
P<0.0001\end{array}$ & $\begin{array}{l}t_{(12)}=12.1698 \\
P<0.0001\end{array}$ & $\begin{array}{l}t_{(12)}=13.2122 \\
P<0.0001\end{array}$ \\
\hline \multirow[t]{4}{*}{ IL-4 } & N vs I-L. DD8 & $\begin{array}{l}t_{(12)}=11.8592 \\
P<0.0001\end{array}$ & $\begin{array}{l}t_{(12)}=11.2109 \\
P<0.0001\end{array}$ & $\begin{array}{l}t_{(12)}=9.6496 \\
P<0.0001\end{array}$ \\
\hline & I-L. DD8 + CsA vs I-L. DD8 & $\begin{array}{l}t_{(12)}=1.1525 \\
P=0.2715\end{array}$ & $\begin{array}{l}t_{(12)}=1.3592 \\
P=0.1991\end{array}$ & $\begin{array}{l}t_{(12)}=1.4827 \\
P=0.1639\end{array}$ \\
\hline & I-L. DD8 + DHCsA-d vs I-L. DD8 & $\begin{array}{l}t_{(12)}=6.8682 \\
P<0.0001\end{array}$ & $\begin{array}{l}t_{(12)}=6.4039 \\
P<0.0001\end{array}$ & $\begin{array}{l}t_{(12)}=5.8037 \\
P<0.0001\end{array}$ \\
\hline & I-L. DD8 + SSG vs I-L. DD8 & $\begin{array}{l}t_{(12)}=8.1166 \\
P<0.0001\end{array}$ & $\begin{array}{l}t_{(12)}=7.9485 \\
P<0.0001\end{array}$ & $\begin{array}{l}t_{(12)}=6.6847 \\
P<0.0001\end{array}$ \\
\hline \multirow[t]{4}{*}{ NO } & N vs I-L. DD8 & $\begin{array}{l}t_{(12)}=14.8865 \\
P<0.0001\end{array}$ & $\begin{array}{l}t_{(12)}=11.2109 \\
P<0.0001\end{array}$ & $\begin{array}{l}t_{(12)}=8.9723 \\
P<0.0001\end{array}$ \\
\hline & I-L. DD8 + CsA vs I-L. DD8 & $\begin{array}{l}t_{(12)}=0.6153 \\
P=0.5498\end{array}$ & $\begin{array}{l}t_{(12)}=0.6931 \\
P=0.5015\end{array}$ & $\begin{array}{l}t_{(12)}=0.5985 \\
P=0.5606\end{array}$ \\
\hline & I-L. DD8 + DHCsA-d vs I-L. DD8 & $\begin{array}{l}t_{(12)}=7.7965 \\
P<0.0001\end{array}$ & $\begin{array}{l}t_{(12)}=5.8653 \\
P<0.0001\end{array}$ & $\begin{array}{l}t_{(12)}=4.72 \\
P=0.0004\end{array}$ \\
\hline & I-L. DD8 + SSG vs I-L. DD8 & $\begin{array}{l}t_{(12)}=7.7822 \\
P<0.0001\end{array}$ & $\begin{array}{l}t_{(12)}=5.6942 \\
P=0.0001\end{array}$ & $\begin{array}{l}t_{(12)}=3.8402 \\
P=0.0024\end{array}$ \\
\hline \multirow[t]{4}{*}{$\mathrm{H}_{2} \mathrm{O}_{2}$} & N vs I-L. DD8 & $\begin{array}{l}t_{(12)}=4.6596 \\
P=0.0006\end{array}$ & $\begin{array}{l}t_{(12)}=5.3572 \\
P=0.0002\end{array}$ & $\begin{array}{l}t_{(12)}=3.3676 \\
P=0.0056\end{array}$ \\
\hline & I-L. DD8 + CsA vs I-L. DD8 & $\begin{array}{l}t_{(12)}=0.9975 \\
P=0.3382\end{array}$ & $\begin{array}{l}t_{(12)}=1.222 \\
P=0.2452\end{array}$ & $\begin{array}{l}t_{(12)}=0.7519 \\
P=0.4666\end{array}$ \\
\hline & I-L. DD8 + DHCsA-d vs I-L. DD8 & $\begin{array}{l}t_{(12)}=4.6618 \\
P=0.0005\end{array}$ & $\begin{array}{l}t_{(12)}=5.405 \\
P=0.0002\end{array}$ & $\begin{array}{l}t_{(12)}=3.4004 \\
P=0.0053\end{array}$ \\
\hline & I-L. DD8 + SSG vs I-L. DD8 & $\begin{array}{l}t_{(12)}=4.6047 \\
P=0.0006\end{array}$ & $\begin{array}{l}t_{(12)}=5.2354 \\
P=0.0002\end{array}$ & $\begin{array}{l}t_{(12)}=3.0176 \\
P=0.0107\end{array}$ \\
\hline
\end{tabular}




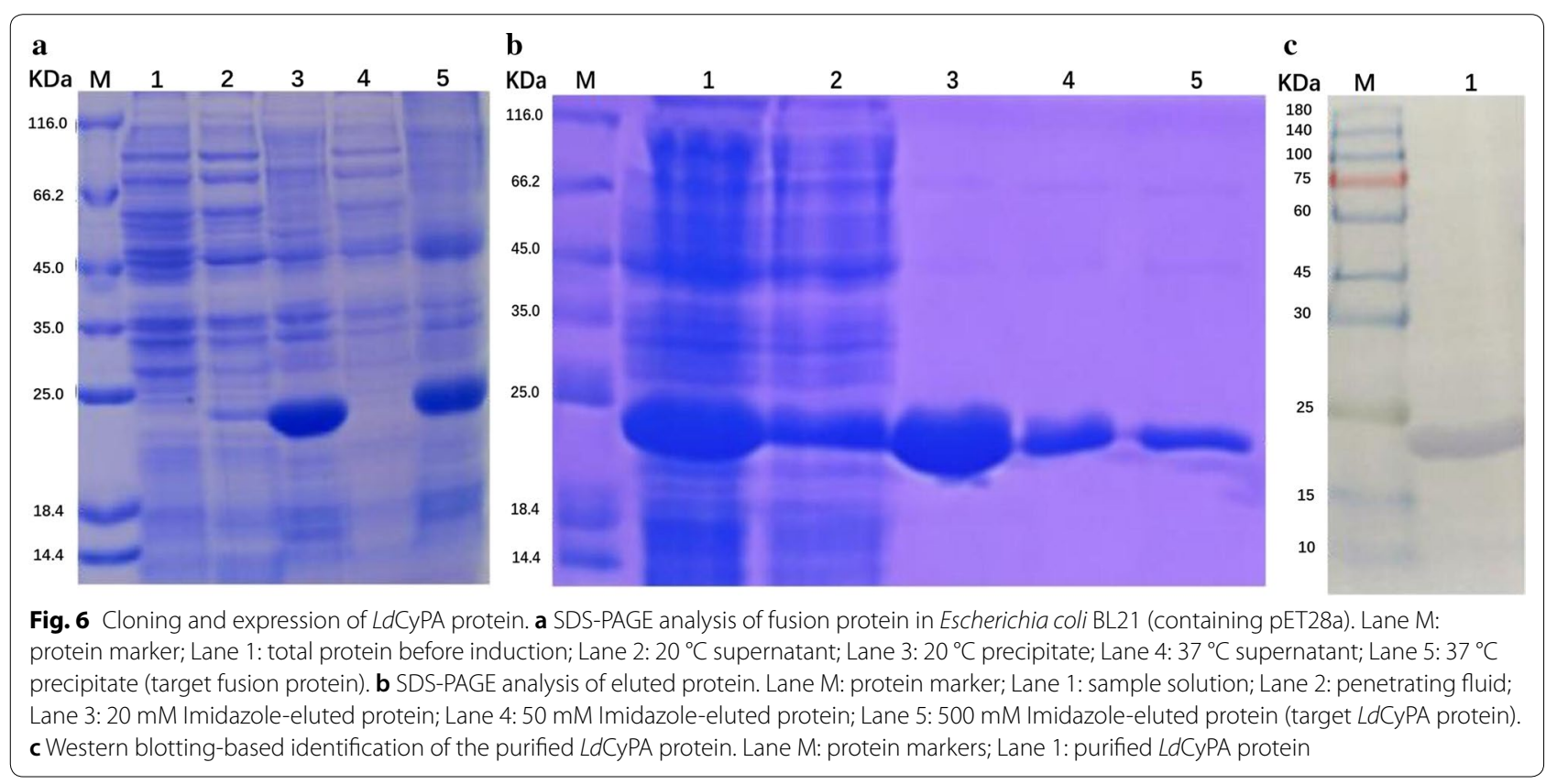

of IL-10 were found in the serum of these VL patients, which could inhibit the activity of pro-inflammatory cytokines, such as IFN- $\gamma$ and TNF- $\alpha$ [29]. Macrophages produce IL-12 to promote a Th1 response during leishmanial infection, which protects the host and controls parasite replication $[30,31]$. Meanwhile, TNF- $\alpha$ and IFN- $\gamma$, implicated to be involved in the activation of macrophages, were also observed to play a role in preventing parasite replication [32]. Previous studies also verified that drugs which have inhibitory effects on $L$. donovani, could decrease IL-10 and IL-4 in VL mice $[4,33,34]$. In this study, the reduction of parasite burden was supported by the increase of IL-12, IFN- $\gamma$ and TNF- $\alpha$ and decrease of IL- 4 and IL-10 after DHCsA$\mathrm{d}$ or SSG treatments. On the contrary, the levels of IL-12, IFN- $\gamma$ and TNF- $\alpha$ decreased and IL-4 and IL-10 increased after CsA treatment compared with those of the untreated group.

In the first few hours of leishmanial infection within macrophages, the most effective anti-parasitic response of the macrophages is the production of reactive oxygen species (ROS) and reactive nitrogen species (RNS) [35, $36]$. The two major reactive species in macrophages are superoxide $\left(\mathrm{O}_{2}{ }^{-}\right)$and nitric oxide (NO) [37, 38]. It is observed that if drugs have ideal anti-parasitic effects, the $\mathrm{NO}$ and $\mathrm{H}_{2} \mathrm{O}_{2}$ productions of leishmania-infected macrophages decrease $[4,39]$. In our research, elevated levels of $\mathrm{NO}$ and $\mathrm{H}_{2} \mathrm{O}_{2}$ were found in leishmaniainfected macrophages and a strong inhibition of $\mathrm{NO}$ and $\mathrm{H}_{2} \mathrm{O}_{2}$ metabolites was observed upon treatment with DHCsA-d or SSG. However, an increase of these metabolites was observed after treatment with CsA. Meissner et al. [40] also found that CsA did not rely on reactive nitrogen to kill $L$. major by macrophages and the NO production was also not increased after CsA treatment.

Cyclophilin A (CyPA), which possesses a peptidylprolyl isomerase (PPIase) activity, is an important member of a highly conserved family of human multi-functional proteins called cyclophilins (CyPs) $[16,17]$. CyPA, having an immunosuppressive action, is characterized by the binding of cyclic peptide inhibitor, CsA, which inhibits protein phosphatase calcineurin and $\mathrm{T}$ cellmediated immunity [11]. Parasite cyclophilins are also known to be potential drug targets, because the immunosuppressive drug CsA can be potentially used as an antiparasitic drug against Leishmania tropica [7], Schistosoma mansoni [22] and Plasmodium falciparum [41]. Trypanosoma cruzi cyclophilin (TcCyP19) is suggested to play a protective role in the survival of the infected tissue and allow parasite persistence [20]. The Leishmania cyclophilin of $19 \mathrm{kDa}, L d C y P A$, has a $79-81 \%$ protein sequence identity with the TcCyP19 [42]. In this study, western blotting showed a decreased expression of CyPA and LdCyPA after CsA treatment, while that of DHCsA-d or SSG groups showed no significant changes. These results confirmed observations in a previous study demonstrating that cell CyPA can inhibit the immunity of macrophages by binding to CsA and that $L d C y P A$ can promote the intracellular viability and proliferation of leishmania by binding to CsA. According to the above results, since CsA is not shown to have 

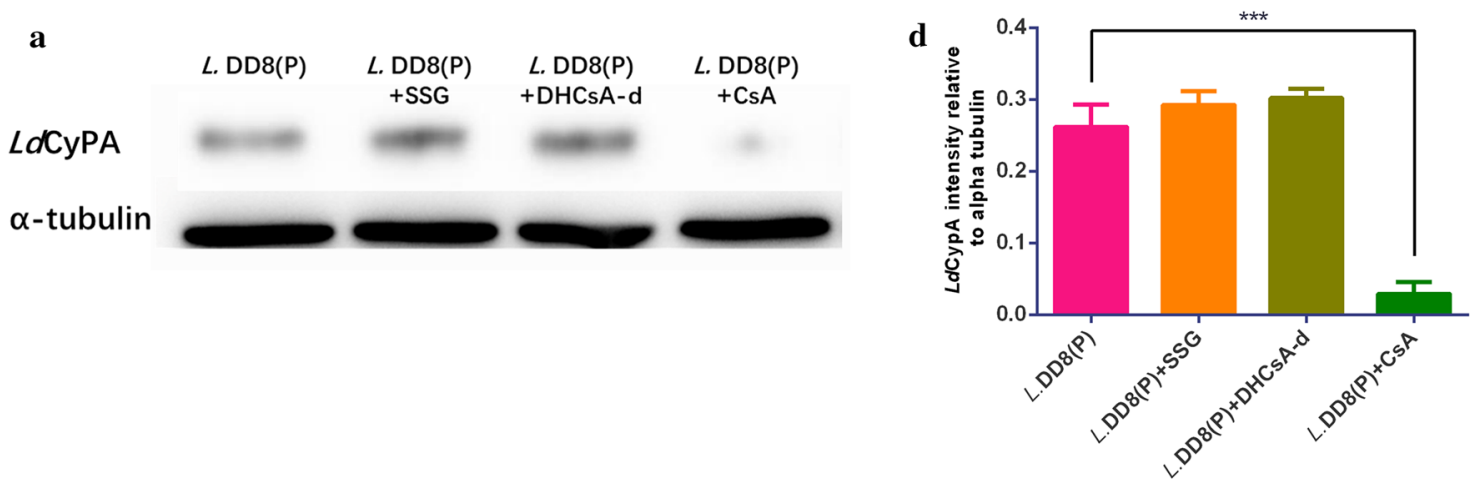

b

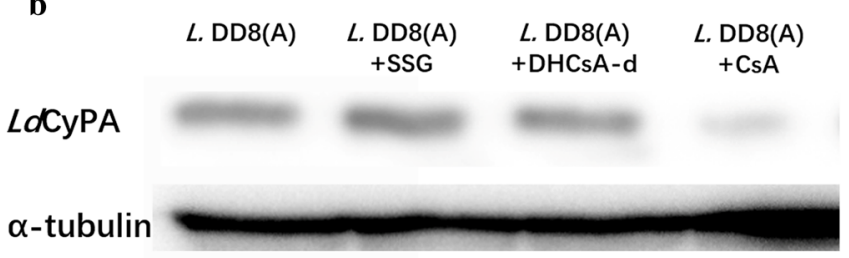

c

CyPA

$\alpha$-tubulin

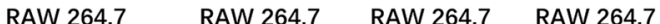

RAW 264.7 RAW 264.7 RAW 264.7 RAW 264.7
+ DHCsA-d

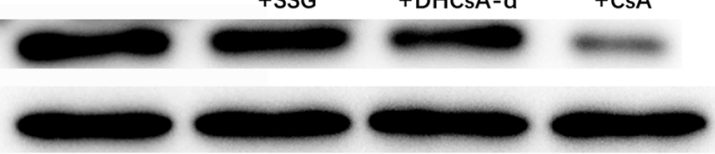

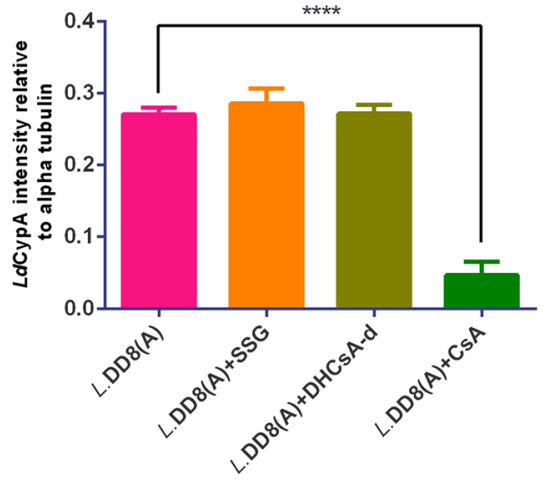

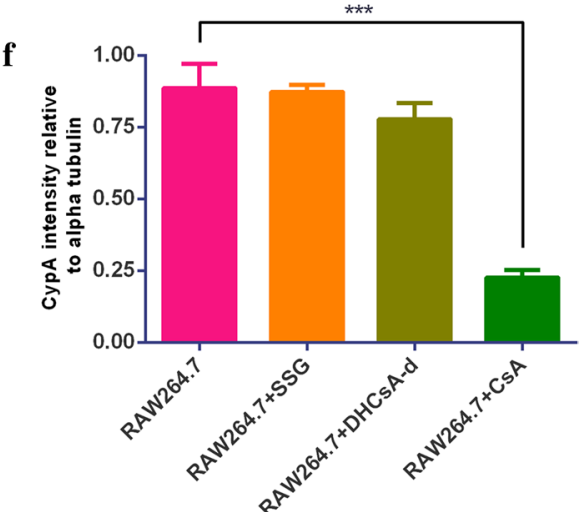

Fig. 7 LdCyPA and CyPA expression after treatment with three drugs. a LdCyPA expression levels of promastigotes treated with SSG, DHCSA-d, or CsA for $48 \mathrm{~h}$; LdCyPA polyclonal antibody and a-tubulin antibody were used as primary antibodies. $\mathbf{b}$ LdCyPA expression levels of intracellular amastigotes treated with SSG, DHCsA-d, or CSA for 48 h; LdCyPA polyclonal antibody and a-tubulin antibody used as primary antibodies. c CyPA expression levels of RAW 264.7 mouse macrophages co-cultured with SSG, DHCsA-d, or CsA at 48 h; CyPA and a-tubulin antibodies used as primary antibodies. Densitometry plot of $L d C y P A$ expression in promastigotes (d) and amastigotes (e) normalized by an endogenous control, $\mathbf{a}$-tubulin. $\mathbf{f}$ Densitometry plot of CyPA expression in RAW264.7 cells, normalized by an endogenous control, a-tubulin. Data are represented as the mean \pm SD and represent the values of one of the 3 independent experiments. ${ }^{* *} P<0.001$, ${ }^{* * *} P<0.0001$. Abbreviations: A, intracellular amastigote; $P$, promastigote

an inhibitory effect on intracellular amastigotes, we believe that CsA should not be recommended for VL treatment.

DHCsA-d had an excellent inhibitory effect on both promastigotes and intracellular amastigotes and did not inhibit the immunological effects of macrophages or promote leishmania infection. Unfortunately, the $\mathrm{CC}_{50}$ of DHCsA-d was only $7.98 \mu \mathrm{M}(24 \mathrm{~h})$ and $6.65 \mu \mathrm{M}$ $(48 \mathrm{~h})$ in this study, suggesting its high cytotoxicity. Therefore, DHCsA-d is also not recommended for 
Table $3 \mathrm{CC}_{50}$ of CsA, DHCsA-d, or SSG used for treatment of RAW 264.7 cells

\begin{tabular}{lll}
\hline Compound & \multicolumn{2}{l}{ Cytotoxicity (RAW 264.7) $\mathrm{CC}_{50}$} \\
\cline { 2 - 3 } & $24 \mathrm{~h}$ & $48 \mathrm{~h}$ \\
& Mean $\pm \mathrm{SD}(\mu \mathrm{M})$ & Mean $\pm \mathrm{SD}(\mu \mathrm{M})$ \\
\hline $\mathrm{CsA}$ & $15.91 \pm 0.2$ & $12.65 \pm 1.2$ \\
DHCSA-d & $7.98 \pm 0.4$ & $6.65 \pm 0.7$ \\
SSG & $>120$ & $>120$
\end{tabular}

Note: Data are represented as the mean \pm SD of three independent experiments

Abbreviations: $\mathrm{CC}_{50}, 50 \%$ cytotoxic concentration; $\mathrm{SD}$, standard deviation

VL treatment. This study demonstrated that CsA and DHCsA-d might not be ideal antileishmanial agents due to various limitations, which may provide a reference for subsequent researches.

\section{Conclusions}

The results of our study have resolved the dispute regarding the efficacy of CsA and DHCsA-d for VL treatment. CsA did not show a significant inhibitory effect on the intracellular amastigotes of $L$. donovani. DHCsA-d significantly inhibited promastigotes and intracellular amastigotes, but it was found to be highly cytotoxic. We believe that CsA and DHCsA-d should not be recommended as antileishmanial drugs. Research towards new therapeutic drugs for VL has a long way to go and further studies are required to develop appropriate anti-leishmanial drugs.

\footnotetext{
Abbreviations

CsA: Cyclosporine A; DHCsA-d: Dihydrocyclosporin A; SSG: Sodium stibogluconate; CyPA: Cyclophilin A; LdCyPA: Leishmania donovani Cyclophilin $A_{i}$ VL: Visceral leishmaniasis; SbV: Pentavalent antimonials; $I_{50}$ : 50\% inhibitory concentration; $\mathrm{CC}_{50}: 50 \%$ cytotoxic concentration; ELISA: Enzyme-linked immunosorbent assay.
}

\section{Acknowledgements}

Not applicable.

\section{Authors' contributions}

JPC, JL, ZWZ and DLC designed and supervised the study. ZWZ, JL, HC, JHZ and QZ undertook the laboratory work. $J \mathrm{~L}$ and ZWZ wrote the manuscript. DLC, JLH and QWC revised the manuscript and polished the language. All authors read and approved the final manuscript.

\section{Funding}

This study was supported by the National Natural Science Foundation of China to JL (31802184), JC (81672048) and DC (31572240, 31872959).

\section{Availability of data and materials}

The datasets supporting the conclusions of this article are included within the article.

\section{Ethics approval and consent to participate}

This study was approved by the Sichuan University Medical Ethics Committee (Approval Number: K2018056). All animal experimental procedures were performed according to the regulations laid down by the Administration of
Affairs Concerning Experimental Animals approved by the State Council of People's Republic of China.

\section{Consent for publication}

Not applicable.

\section{Competing interests}

The authors declare that they have no competing interests.

\section{Author details}

1 Department of Pathogenic Biology, West China School of Basic Medical Sciences and Forensic Medicine, Sichuan University, Chengdu, China. ${ }^{2}$ Animal Disease Prevention and Food Safety Key Laboratory of Sichuan Province, Chengdu, China.

Received: 4 November 2019 Accepted: 10 February 2020 Published online: 21 February 2020

\section{References}

1. Alvar J, Velez ID, Bern C, Herrero M, Desjeux P, Cano J, et al. Leishmaniasis worldwide and global estimates of its incidence. PLOS ONE. 2012; 7:e35671.

2. Lun ZR, Wu MS, Chen YF, Wang JY, Zhou XN, Liao LF, et al. Visceral leishmaniasis in China: an endemic disease under control. Clin Microbiol Rev. 2015;28:987-1004.

3. Guerin PJ, Olliaro P, Sundar S, Boelaert M, Croft SL, Desjeux P, et al. Visceral leishmaniasis: current status of control, diagnosis and treatment and a proposed research and development agenda. Lancet Infect Dis. 2002;2:494-501.

4. Chauhan K, Kaur G, Kaur S. Activity of rutin, a potent flavonoid against SSG-sensitive and -resistant Leishmania donovani parasites in experimental leishmaniasis. Int Immunopharmacol. 2018;64:372-85.

5. Bell A, Roberts $\mathrm{HC}$, Chappell LH. The antiparasite effects of cyclosporin A: possible drug targets and clinical applications. Gen Pharmacol. 1996;27:963-71.

6. Chappell LH, Wastling JM. Cyclosporin A: antiparasite drug, modulator of the host-parasite relationship and immunosuppressant. Parasitology. 1992;105(Suppl.):25-40.

7. Solbach W, Forberg K, Kammerer E, Bogdan C, Rollinghoff M. Suppressive effect of cyclosporin A on the development of Leishmania tropicainduced lesions in genetically susceptible BALB/c mice. J Immunol. 1986;137:702-7.

8. Solbach W, Forberg K, Rollinghoff M. Effect of T-lymphocyte suppression on the parasite burden in Leishmania major-infected, genetically susceptible BALB/c mice. Infect Immun. 1986;54:909-12.

9. Hoerauf A, Rascher C, Bang R, Pahl A, Solbach W, Brune K, et al. Hostcell cyclophilin is important for the intracellular replication of Leishmania major. Mol Microbiol. 1997;24:421-9.

10. Eldaw A, Sequeira RP, Eldirdiri AB. A preliminary observation on in vitro inhibitory effect of cyclosporin-A upon growth of Leishmania tropica promastigotes. J Egypt Soc Parasitol. 1989;19:301-5.

11. Yau WL, Blisnick T, Taly JF, Helmer-Citterich M, Schiene-Fischer C, Leclercq O, et al. Cyclosporin A treatment of Leishmania donovani reveals stage-specific functions of cyclophilins in parasite proliferation and viability. PLoS Negl Trop Dis. 2010;4:e729.

12. Merelli M, Quartuccio L, Bassetti M, Pecori D, Gandolfo S, Avellini C, et al. Efficacy of intravenous cyclosporine in a case of cytophagic histiocytic panniculitis complicated by haemophagocytic syndrome after visceral leishmania infection. Clin Exp Rheumatol. 2015;33:906-9.

13. Adinolfi LE, Bonventre PF. Cyclosporin A treatment converts Leishmania donovani-infected C57BL/10 (curing) mice to a noncuring phenotype. Infect Immun. 1990;58:3151-3.

14. Olivier M, Proulx C, Tanner CE. Importance of lymphokines in the control of multiplication and dispersion of Leishmania donovani within liver macrophages of resistant and susceptible mice. J Parasitol. 1989;75:720-7.

15. Olivier $M$, Tanner CE. The effect of cyclosporin A in murine visceral leishmaniasis. Trop Med Parasitol. 1989:40:32-8. 
16. Roberts HC, Sternberg JM, Chappell LH. Characterization of calcineurin from Hymenolepis microstoma and $\mathrm{H}$. diminuta and its interaction with cyclosporin A. Parasitology. 1997;114:279-83.

17. Xue C, Sowden MP, Berk BC. Extracellular and intracellular cyclophilin A, native and post-translationally modified, show diverse and specific pathological roles in diseases. Arterioscler Thromb Vasc Biol. 2018;35:986-93.

18. Peacock CS, Seeger K, Harris D, Murphy L, Ruiz JC, Quail MA, et al. Comparative genomic analysis of three Leishmania species that cause diverse human disease. Nat Genet. 2007;39:839-47.

19. Rogers MB, Hilley JD, Dickens NJ, Wilkes J, Bates PA, Depledge DP, et al. Chromosome and gene copy number variation allow major structura change between species and strains of Leishmania. Genome Res. 2011;21:2129-42.

20. Perrone AE, Milduberger N, Fuchs AG, Bustos PL, Bua J. A functional analysis of the cyclophilin repertoire in the protozoan parasite Trypanosoma cruzi. Biomolecules. 2018;8:E132.

21. Meier GP, Park SB, Yee GC, Gmur DJ. Isolation and identification of a novel human metabolite of cyclosporin A: dihydro-CsA M17. Drug Metab Dispos. 1990;18:68-71.

22. Chappell LH, Thomson AW, Barker GC, Smith SW. Dosage, timing, and route of administration of cyclosporin $A$ and nonimmunosuppressive derivatives of dihydrocyclosporin $A$ and cyclosporin $C$ against Schistosoma mansoni in vivo and in vitro. Antimicrob Agents Chemother. 1987;31:1567-71.

23. Veronica J, Chandrasekaran S, Dayakar A, Devender M, Prajapati VK, Sundar S, et al. Iron superoxide dismutase contributes to miltefosine resistance in Leishmania donovani. FEBS J. 2019;286:3488-503.

24. Vermeersch $M$, da Luz RI, Tote K, Timmermans JP, Cos P, Maes L. In vitro susceptibilities of Leishmania donovani promastigote and amastigote stages to antileishmanial reference drugs: practical relevance of stagespecific differences. Antimicrob Agents Chemother. 2009;53:3855-9.

25. ter Horst R, Collin SM, Ritmeijer K, Bogale A, Davidson RN. Concordant HIV infection and visceral leishmaniasis in Ethiopia: the influence of antiretroviral treatment and other factors on outcome. Clin Infect Dis. 2008;46:1702-9.

26. Teixeira de Macedo Silva S, Visbal G, Lima Prado Godinho J, Urbina JA, de Souza W, Cola Fernandes Rodrigues J. In vitro antileishmanial activity of ravuconazole, a triazole antifungal drug, as a potential treatment for leishmaniasis. J Antimicrob Chemother. 2018;73:2360-73.

27. de Macedo-Silva ST, Urbina JA, de Souza W, Rodrigues JC. In vitro activity of the antifungal azoles itraconazole and posaconazole against Leishma nia amazonensis. PLoS ONE. 2013;8:e83247.

28. Mukbel RM, Patten C Jr, Gibson K, Ghosh M, Petersen C, Jones DE. Macrophage killing of Leishmania amazonensis amastigotes requires both nitric oxide and superoxide. Am J Trop Med Hyg. 2007;76:669-75.
29. Faleiro RJ, Kumar R, Hafner LM, Engwerda CR. Immune regulation during chronic visceral leishmaniasis. PLoS Negl Trop Dis. 2014;8:e2914.

30. Hernandez-Pando R, Orozco H, Arriaga K, Sampieri A, Larriva-Sahd J, Madrid-Marina $V$. Analysis of the local kinetics and localization of interleukin-1 alpha, tumour necrosis factor-alpha and transforming growth factor-beta, during the course of experimental pulmonary tuberculosis. Immunology. 1997;90:607-17.

31. Watford WT, Hissong BD, Bream JH, Kanno Y, Muul L, O'Shea JJ. Signaling by IL-12 and IL-23 and the immunoregulatory roles of STAT4. Immunol Rev. 2004;202:139-56.

32. Rossi M, Fasel N. How to master the host immune system? Leishmania parasites have the solutions! Int Immunol. 2018;30:103-11.

33. Kaur R, Kaur S. Evaluation of in vitro and in vivo antileishmanial potential of bergenin rich Bergenia ligulata (Wall.) Engl. root extract against visceral leishmaniasis in inbred BALB/c mice through immunomodulation. J Tradit Complement Med. 2018:8:251-60.

34. Lapara NJ 3rd, Kelly BL. Suppression of LPS-induced inflammatory responses in macrophages infected with Leishmania. J Inflamm. 2010;7:8.

35. Iles KE, Forman HJ. Macrophage signaling and respiratory burst. Immunol Res. 2002;26:95-105.

36. Fang FC. Antimicrobial reactive oxygen and nitrogen species: concepts and controversies. Nat Rev Microbiol. 2004;2:820-32.

37. Panday A, Sahoo MK, Osorio D, Batra S. NADPH oxidases: an overview from structure to innate immunity-associated pathologies. Cell Mol Immunol. 2015:12:5-23.

38. Aktan F. iNOS-mediated nitric oxide production and its regulation. Life Sci. 2004:75:639-53.

39. Pereira AV, de Barros G, Pinto EG, Tempone AG, Orsi Rde O, Dos Santos LD, et al. Melittin induces in vitro death of Leishmania (Leishmania) infantum by triggering the cellular innate immune response. J Venom Anim Toxins Incl Trop Dis. 2016:22:1.

40. Meissner U, Juttner S, Rollinghoff M, Gessner A. Cyclosporin A-mediated killing of Leishmania major by macrophages is independent of reactive nitrogen and endogenous TNF-alpha and is not inhibited by IL-10 and 13 . Parasitol Res. 2003:89:221-7.

41. Bell A, Wernli B, Franklin RM. Roles of peptidyl-prolyl cis-trans isomerase and calcineurin in the mechanisms of antimalarial action of cyclosporin A, FK506, and rapamycin. Biochem Pharmacol. 1994:48:495-503.

42. Bua J, Aslund L, Pereyra N, Garcia GA, Bontempi EJ, Ruiz AM. Characterisation of a cyclophilin isoform in Trypanosoma cruzi. FEMS Microbiol Lett. 2001;200:43-7.

\section{Publisher's Note}

Springer Nature remains neutral with regard to jurisdictional claims in published maps and institutional affiliations.
Ready to submit your research? Choose BMC and benefit from:

- fast, convenient online submission

- thorough peer review by experienced researchers in your field

- rapid publication on acceptance

- support for research data, including large and complex data types

- gold Open Access which fosters wider collaboration and increased citations

- maximum visibility for your research: over $100 \mathrm{M}$ website views per year

At BMC, research is always in progress.

Learn more biomedcentral.com/submissions 